\title{
TRANSIÇÃO POLÍTICA E CONSOLIDAÇÃO DEMOCRÁTICA NO BRASIL: NOVAS REFLEXÕES SOBRE UM VELHO TEMA
}

\author{
Vania Sandeleia Vaz da Silva
}

Os processos de transição política e consolidação democrática no Brasil podem ser considerados um excelente laboratório de Ciência Política, tanto pela longa duração, como pela variedade dos eventos que marcam tal período da história brasileira recente. Vencida a cláusula de alternância no poder - estamos no segundo mandato de um torneiro mecânico de profissão, ex-sindicalista, participante das lutas da sociedade civil pela (re)democratização do país, ou seja, definitivamente alguém que não pertence à elite tradicional do país -, pode-se dizer que a democracia brasileira está consolidada. Mas o que isso significa? O passado autoritário ou ditatorial terá sido extirpado? Quais suas heranças? Qual a influência do passado no que vemos (e vivemos) atualmente, do ponto de vista político? Como compreender a mudança (ou será transformação)? Valerá o esforço de debruçar-se novamente sobre isso? O tema é instigante porque desperta o interesse em, pelo menos, duas dimensões: do ponto de vista teórico ou acadêmico, pois, embora muito já tenha sido descoberto, escrito e revisado, ainda existem aspectos não abordados ou não esgotados; e também pelo fato de dizer respeito a todos nós, brasileiros, e, num mundo cada vez mais interdependente, aos cidadãos de qualquer nacionalidade que consideram a democracia melhor do que formas mais autoritárias ou menos participativas de governar. Mas será esse o caso do Brasil?

O livro Political Transition and Democratic Consolidation: Studies on Contemporary Brazil, editado pelo professor Adriano Nervo Codato, constitui uma valiosa ferramenta para pesquisadores estrangeiros interessados nas transformações recentes por que passou nosso país - na medida em que sua publicação em inglês o torna acessível -, mas também pode ser considerado um referencial para qualquer pessoa que deseja tomar contato com o tema - ou até mesmo se especializar em determinadas questões -, uma vez que aborda diversos aspectos envolvidos no processo de mudança de regime político no Brasil, condensando vários anos de pesquisa e reflexão dos autores envolvidos. Para uma referência histórica dos principais eventos, pode-se iniciar a leitura do livro pelo oitavo capítulo - A Chronology of Brazilian Political History: 1960/2002 -, que constitui um excelente guia para consulta dos principais eventos do período, selecionados e apresentados por Marcos Napolitano. Trata-se de uma cronologia detalhada da história política brasileira de 1960 até 2002, a qual ressalta fatos que cobrem três dimensões: social, econômica e política. Os subtítulos são ilustrativos: para os anos 1960, "Reformas, golpe militar e revolução"; para a década de 1970, "Autoritarismo, desenvolvimento econômico e movimentos por democracia"; para os anos 1980, "Transição democrática, governo civil e crise econômica"; para a década de 1990, "Neo-liberalismo, democracia e globalização". A seqüência termina em 2002, com a eleição de Luiz Inácio Lula da Silva para Presidente da República, reeleito em 2006.

Timothy Power, prefaciador do volume, enfatiza quatro aspectos de seu conteúdo, essenciais para repensar a história recente brasileira: 1) o questionamento do voluntarismo, a partir de uma contextualização e revitalização da autonomia da esfera política; 2) a descrição da democracia brasileira como é e não como deveria ser - ou seja, em relação aos regimes democráticos vigentes no oeste Europeu e nos Estados Unidos; 3) o fato de que a democracia é pensada holisticamente, superando uma política comparativa que se restringe ao nível do regime e 4) a expansão da definição procedimental de democracia - que é tomada como ponto de partida - incluindo temas como a eqüidade, o desenvolvimento sustentável e a inclusão social. Os pesquisadores, seis brasileiros e um francês, de acordo com Codato, reconceituam a mudança macropolítica no Brasil, e têm como principal objetivo analisar formas de discutir e explicar esse período particularmente interessante da história brasileira - desde os primeiros abalos na ditadura militar (ou regime autoritário) até a tendência para a consolidação de um regime democrático -, concentrando-se no questionamento dos modelos teóricos dominantes da Ciência Política que foram utilizados, até então, na análise desse processo de mudança política. 
No primeiro capítulo - "Political Transition and Democratic Consolidation in Brazil: a Historical Perspective"-, Adriano Nervo Codato, ao refazer a história política nacional a partir de 1974, procura indicar variáveis que influíram na configuração política e institucional do atual regime. Defende que os militares iniciaram o processo de transição política, determinaram sua natureza, andamento e objetivos. Partindo da história concreta para a compreensão e análise teórica, enfatiza a continuidade e chega à seguinte periodização do cenário político: de 1964 até 1974, temos um regime ditatorial; entre 1974 e 1989, um período de transição; e, de 1989 até 2002, um intervalo de consolidação de um novo regime, nomeado pelo autor como liberaldemocrático. Sua hipótese é de que as tipologias construídas pela literatura para analisar a dinâmica da transição e consolidação não atentaram o suficiente para os determinantes históricos que condicionaram a relação entre as Forças Armadas, o Estado e a sociedade no Brasil. Propõe uma interpretação para o processo histórico (de 1974 a 2002) baseada em quatro questões, que constituem um bom ponto de partida para pensar todo o processo e compreender o seu resultado: 1) o que muda ou: que instituições políticas são suprimidas, restauradas ou transformadas nesse processo? 2) Como muda ou: qual a natureza do processo que governa a mudança? 3) Por que muda ou: quais as razões da substituição de um modelo político por outro? 4) Em que direção muda ou: qual é o significado mais amplo da mudança política? Conclui que há uma continuidade entre o "regime autoritário" e o autoritarismo no regime liberal-democrático, garantido pela herança institucional da ditadura militar: a permanência de núcleos de poder específicos no Estado, dotados de grande independência e nenhum controle político (parlamentar) ou social (público). A continuidade é dada por uma complementaridade entre o discurso ideológico liberal e as práticas políticas autoritárias, que, por exemplo, nos governos de Fernando Henrique Cardoso (1995-2002), foi expressa na predominância da construção da hegemonia do capitalismo neoliberal sobre a ampliação da participação ou da cidadania: as reformas econômicas (como as privatizações) não só prescindiram de uma verdadeira reforma política (que poderia ampliar a representação) ou social (que favorecesse a participação), mas tiveram como precondição o arranjo autoritário dos processos de governo e a ausência de accountability dos governantes. Mais do que uma mudança, o que se verifica é um deslocamento do autoritarismo que permanece como prática, ou de fato, no regime liberal-democrático.

No segundo capítulo - "State and Regime in Post-64 Brazil: Bureaucratic Authoritarianism or Military Dictatorship?" -, João Roberto Martins Filho analisa a dimensão militar da dinâmica política posterior a 1964, atentando para a especificidade da prática política das Forças Armadas e sua heterogeneidade, divisão interna e fluidez. Discute a hipótese hegemônica sobre o período que enfatiza o caráter autoritário do regime brasileiro posterior a 1964 e sua dinâmica burocrática. Analisa as teses de Guillermo O’Donnell a respeito do novo autoritarismo que emergiu na América Latina depois de uma série de golpes militares bem-sucedidos (Brasil, 1964; Argentina, 1966 e 1976; Uruguai, 1973; Chile, 1973) e questiona a idéia de autoritarismo burocrático usada para caracterizar essas novas formas de dominação política, afirmando que tal abordagem deixou de considerar a natureza militar-ditatorial do regime. Definir um arranjo político como burocrático não especifica, já que tal definição é comum aos Estados de sociedades capitalistas: o que é diferente é a militarização do Estado e o papel particular que as Forças Armadas ocuparam no Brasil. Critica também Alfred Stepan pelo papel que confere aos militares no gerenciamento do regime brasileiro e, de modo geral, a noção de homogeneidade e a concepção burocrática das Forças Armadas. As análises que se apóiam na noção de regime autoritário realizam uma descrição do processo de burocratização do Estado que enfatiza o papel da elite burocrática e não utilizam o conceito de ditadura militar (que seria mais preciso), além de não atribuir a devida importância ao processo de militarização do Estado e ao papel decisivo das Forças Armadas, cuja unidade (crítica) foi construída por meio de uma ideologia militar de rejeição unânime da política civil, mais precisamente de um retorno ao populismo. Mas tal unidade convivia com sérias divisões, configuradas por dois processos separados: "disunity expresses itself differently within the hierarchy (discord regarding presidential succession) and within officialdom (divisions in the barracks, related to expectations of direct influence on the government)"1 (MARTINS FILHO, 2006, p. 43). A estabilidade da ditadura militar (brasileira) era um mito, pois, na verdade, constituía não apenas uma forma de Estado de crise, porque emergiu de uma crise específica, mas também era uma forma crítica de Estado, marcada por um tipo específico de instabilidade só compreendida pelo estudo da sua dinâmica intramilitar.

O terceiro capítulo - "Delegative Democracy or Vicissitudes of Transition?" - apresenta várias críticas do autor, Ricardo Silva, a Guillermo O'Donnell, sobretudo ao conceito de democracia delegativa elaborado para entender os resultados dos processos de transição política na América Latina. Ao contrário da democracia

\footnotetext{
1 “A desunião expressa-se a si mesma diferentemente na hierarquia (discórdia relativa à sucessão presidencial) e no
} oficialato (divisões nos quartéis, relativas às expectativas de influência direta no governo)" (nota do revisor). 
representativa, os novos regimes são entendidos por O’Donnell como uma fase histórica intermediária democracia delegativa -, que, embora bloqueie a regressão para os regimes burocráticos autoritários, também constitui um obstáculo para a consolidação da democracia liberal na região. Testando esse modelo com base no caso brasileiro, Silva verifica que o que acontece é o oposto, pois a prática política da sociedade civil brasileira foi dirigida para questionar tanto a irresponsabilidade do governo em relação aos eleitores (accountability vertical) como a irresponsabilidade de quem ocupa o Executivo em relação às outras instituições políticas (accountability horizontal). Assim, o mais apropriado, de acordo com Silva, seria falar de comportamentos delegativos dentro de instituições representativas, ao invés de considerar a emergência de uma nova forma de democracia. Enquanto O’Donnell considera que são fatores históricos de longo prazo e o grau de profundidade da crise política que mais pesam para gerar novos tipos de democracia, Silva afirma que o processo de transição - a forma pela qual se processou a mudança - é que explica a configuração do novo regime. No que diz respeito ao processo de consolidação, Silva é bastante exigente e considera que "only through the transformation of political democracy into social democracy can we expect to eventually see a genuinely consolidated democratic regime"2 (SILVA, 2006, p. 57), ou seja, para o autor, o horizonte é uma democracia social, com tudo o que implica.

No quarto capítulo - "Democracy, Transition and Consolidation: Reworking Misused Concepts"-, Stéphane Monclaire rediscute os conceitos de democracia, transição e consolidação. Analisa duas perspectivas sobre a mudança política - transitologia e consolidologia - cuja literatura referida teve duas fases distintas. $\mathrm{Na}$ primeira, uma visão condicionalista procurava identificar quais as precondições para o desenvolvimento da democracia - dito de outro modo, que fatores propiciam uma mudança de outra forma política para a democracia, o que gerou três abordagens, baseadas nos níveis de desenvolvimento econômico, nas formas históricas de configuração da estrutura social e no tipo dominante de cultura política. Na segunda vertente, uma visão probabilista afirmava que a passagem dos regimes autoritários para os democráticos, definidos em termos shumpeterianos, era uma possibilidade que emergia da ação estratégica de atores politicamente relevantes. Já os estudos de consolidologia - estudo das condições institucionais que tornam viável uma democracia efetiva - consideravam importante analisar o grau em que as regras da democracia foram institucionalizadas dentro de novos regimes, bem como sua legitimidade política e o grau de consenso social que foi gerado em torno da democracia. Monclaire demonstra a inconsistência dessa corrente em dois pontos principais: uma visão simplista dos processos pelos quais as regras e valores são internalizados em uma dada sociedade; e um foco exagerado sobre as instituições políticas e regras constitucionais no entendimento do atual funcionamento de um dado regime. Conclui que "the theses of transitologists and consolidologists, through their object, the questions they pose and the answers offered, are much closer to illusion - that is, they are either partially or very completely replete with assumptions, value judgments, epistemological notions and methodological biases that produce illusion - than to confirmed science"3 (MONCLAIRE, 2006, p. 73).

O quinto capítulo - "The Theoretical Debate on Changes in Political Regimes: the Brazilian Case" - contém uma análise a respeito do debate teórico sobre a mudança de regime político. Carlos Arturi considera a longa duração e o gradualismo da transição brasileira para o regime democrático como um caso privilegiado para verificar a validade de várias hipóteses a respeito da "terceira onda" de democratização, e procura relacionar o processo de transição no Brasil com a inflexão nas perspectivas analíticas sobre mudanças de regime político. Tendo como foco o caso brasileiro, Arturi examina a transição política para a democracia por meio de uma perspectiva que procura escapar do dilema "ator político versus estrutura econômica e social". Defende a combinação de variáveis macroestruturais - como nível de desenvolvimento econômico e estrutura de classe - com variáveis micropolíticas - centradas em torno da qualidade da liderança política e nas escolhas racionais dos atores, tal como a utilização de seus recursos políticos. Essa perspectiva intermediária ganha importância, no caso brasileiro, em dois aspectos: por sua origem no modo de transição gradual, controlado, pactuado, por um lado, e, também, pelas características tradicionais dos arranjos políticos nacionais - a tutela militar sobre o

\footnotetext{
2 "Somente por meio da transformação da democracia política em democracia social podemos esperar finalmente ver um regime democrático genuinamente consolidado" (nota do revisor).

3 "As teses dos transitologistas e dos consolidologistas, por meio de seu objeto, das questões que eles formulam e das respostas que oferecem, estão muito mais próximas da ilusão - isto é, elas são parcial ou completamente repletas de pressupostos, juízos de valor, noções epistemológicas e vieses metodológicos que produzem ilusão - que da ciência comprovada" (nota do revisor).
} 
sistema político, o uso das eleições para resolver conflitos e competições entre a elite política. Afirma que o modo de transição exerceu grande influência no resultado dos processos de transição e na configuração dos constrangimentos para a consolidação do novo regime democrático no Brasil - a autonomização da transição, ao invés de provocar uma ruptura institucional com o antigo regime, enquadrou o processo no padrão institucional tradicional do país, reforçando as características que tornaram o sistema político resistente tanto a ditaduras clássicas quanto a sua democratização estável. Conclui que "the political dilemmas behind democratic consolidation originating in the transition process should be seem together with those that emerges from economic crisis, social inequality and the deep changes in the role of the State that is going on in Brazil today", de modo que "the consolidation of Brazilian democracy today (2001) is still just one possibility among others" 4 (ARTURI, 2006, p. 99).

No sexto capítulo - "Autonomous Participation and Political Institutions in Recent Brazilian Democracy" -, Alberto Tosi Rodrigues propõe uma interpretação a respeito das mobilizações e desmobilizações políticas da sociedade como a contrapartida dos processos de ampliação (socialização) ou estreitamento (privatização) dos canais institucionais que regulam a interação dos atores no conflito sociopolítico. Critica o pensamento conservador que correlaciona diretamente mobilização social com disfuncionalidades políticas sistêmicas de caráter desorganizador e desagregador, ou seja, interpretações que defendem uma correlação direta entre mobilização social (participação) e crise política, afirmando que a mobilização social (por consumo e bem-estar) gera uma sobrecarga de demandas que não são passíveis de atendimento por governos de países em desenvolvimento; ou que a governabilidade dos regimes democráticos (de tais países) seria prejudicada pelo aumento da participação (e politização das demandas). Aponta para uma questão interessante a respeito da construção de uma institucionalidade híbrida e do estreitamento dos espaços de mobilização da democracia brasileira, a partir da constatação da constituição de dois pólos político-ideológicos que tratam diferentemente de questões fundamentais do processo de democratização: os problemas do Estado; da estruturação do regime; e da participação. É importante ressaltar que se trata de um texto escrito no início de 1998, contexto em que a esquerda (na oposição) buscava desprivatizar o Estado; equalizar de modo regrado a competição política; e tratar o problema da participação enquanto mobilização da sociedade organizada em moldes autônomos; enquanto a direita (então no poder) buscava o Estado mínimo; valia-se das reminiscências oligárquicas em termos de regime; e buscava a contenção da mobilização da sociedade organizada e a cooptação das amplas parcelas desorganizadas da população. Rodrigues concluía que os avanços eleitorais da esquerda apontavam para "novos picos de mobilização", enquanto a direita tornava-se hegemônica (a leitura de seu trabalho pode iluminar muitos aspectos da atual correlação de forças no cenário político brasileiro, sobretudo a respeito dos rumos da esquerda).

O sétimo capítulo - "Paths to Democratization in Brazil: Consolidation of a Majoritarian Model of Democracy?" - contém uma discussão da trajetória da democratização no Brasil. Luzia Helena Herrmann de Oliveira analisa questões teóricas da consolidação democrática no Brasil considerando que o modelo poliárquico de Dahl tratado como referencial das democracias estáveis - não se adapta à análise dos processos de democratização em países com passado autoritário. Por isso, compara o funcionamento das instituições políticas brasileiras com o daquelas dos países do sul da Europa - Itália, Grécia, Portugal e Espanha -, que, embora fossem democracias novas, eram já consideradas consolidadas. Afirma que o caso brasileiro tende mais para um modelo de consolidação via elites, embora tenha sido decisivo, para o processo de consolidação, o apoio aberto da opinião pública, das organizações e dos partidos políticos à democracia. Defende que a consolidação democrática envolve elementos que vão além da governabilidade, na medida em que, independentemente dos problemas relativos à preservação do sistema político e da eficácia dos governos, há que se considerar a qualidade da democracia que foi construída. Analisa em que medida a relação entre partidos e governos no Brasil tendia - naquele momento para a consolidação de um modelo majoritário de democracia: destaca a relação entre os poderes Executivo e Legislativo e, apoiando-se no estudo de Lijpart et alii (1988), analisa em que medida as novas democracias tendem mais para modelos majoritários - em que o poder fica concentrado na maioria de governo - ou consorciativos - em que o poder resta equilibrado entre o maior número possível de partidos, inclusive da oposição. Conclui que,

\footnotetext{
4 “Os dilemas políticos por trás da consolidação democrática originados no processo de transição deveriam ser vistos em conjunto com aqueles que surgem da crise econômica, da desigualdade social e das profundas mudanças no papel do Estado por que passa o Brasil hoje", de modo que "a consolidação da democracia brasileira hoje (2001) é ainda apenas uma possibilidade entre outras".
} 
no Brasil, naquele momento, embora o poder Executivo predominasse, o Legislativo possuía atuação relevante, e aproveitava produtivamente seu reduzido campo de atuação.

É evidente que o conteúdo do livro é bem mais rico do que é possível expressar em poucas linhas. O objetivo aqui é apenas incitar a curiosidade para a leitura da obra como um todo. Cada capítulo é um universo particular: embora aborde mais ou menos o mesmo processo, os eventos, atores e modelos são enquadrados dentro de uma perspectiva particular, com preocupações específicas, desenvolvidas com base no objeto investigado. Algo que os diversos trabalhos que compõem o livro têm em comum - além do fato de representarem sinteses de pesquisas mais amplas e aprofundadas realizadas pelos autores - é o questionamento das teses hegemônicas da literatura precedente. Assim, cada capítulo conduz o leitor para detalhes que antes tinham passado despercebidos; ou convida a uma visão mais ampla, acrescentando novos significados aos eventos. Além disso, cada autor apresenta uma revisão e análise competente da literatura mais importante sobre o tema, de modo que pode funcionar como um atalho para a vasta produção bibliográfica a respeito das questões abordadas. A maior vantagem desse trabalho é sua publicação numa língua que possibilitará o acesso - para pesquisadores ou curiosos estrangeiros - a uma produção teórica bem elaborada a respeito da história brasileira recente.

Apenas a título de inquietação - não tão pessoal quanto possa parecer -, considero que os diversos trabalhos dessa obra resolvem bem um dos problemas da maior parte da literatura sobre transição política $\mathrm{e}$ consolidação democrática no Brasil, que é o apego ao modelo minimalista de democracia - cuja referência teórica é a definição procedimental de inspiração schumpeteriana, depois sofisticada pelo conceito de poliarquia de Dahl, e cuja referência empírica são as democracias anglo-saxônicas. Contudo, a ênfase na continuidade bem fundamentada, é verdade - e um certo pessimismo - derivado, acredito, do foco no poder político, concentrado no Estado - mantêm a sociedade civil marginal ao processo - ou com uma influência "mais no ritmo do que no curso dos acontecimentos", como defende Codato. Seria interessante questionar em que medida são os fatos ou o modo de interpretar a realidade que determinam o enquadramento das questões levantadas, que requerem um tipo específico de resposta, guiando o pesquisador para a investigação de estruturas ou atores hegemônicos e, desse modo, subestimando o impacto de outros.

O maior defeito do livro transcende seus limites e objetivos: é a falta de um estudo que incorpore o período posterior a 2002. Ou seja, que repense conceitos como mudança - palavra muito enfatizada nos primeiros discursos de Lula como Presidente da República eleito - e democracia, bem como seus opostos - continuidade, autoritarismo. A maior qualidade é, justamente, relativizar ou requalificar esses termos, de modo que não parece mais tão fácil classificar o regime atual - será necessário? - nem estranho formar frases aparentemente ilógicas como "democracia autoritária".

Vania Sandeleia Vaz da Silva (vania_sandeleia@yahoo.com.br) é Graduada em Ciências Sociais pela Universidade Federal do Paraná, Mestre em Ciência Política pela Universidade de São Paulo (USP) e doutoranda em Ciência Política pela mesma instituição, com bolsa do Conselho Nacional de Desenvolvimento Científico e Tecnológico $(\mathrm{CNPq})$.

\section{REFERÊNCIAS BIBLIOGRÁFICAS}

ARTURI, C. S. 2006. The Theoretical Debate on Changes in Political Regimes : The Brazilian Case. In :CODATO, A. N. (ed.). Political Transition and Democratic Consolidation: Studies on Contemporary Brazil. New York : Nova Science.

CODATO, A. N. (ed.). 2006a. Political Transition and Democratic Consolidation : Studies on Contemporary Brazil. New York : Nova Science.

2006b. Introduction: Interpretations of the Process of Political Change. In : (ed.). Political Transition and Democratic Consolidation : Studies on Contemporary Brazil. New York : Nova Science.

2006c. Political Transition and Democratic Consolidation in Brazil : a Historical Perspective. In :

(ed.). Political Transition and Democratic Consolidation : Studies on Contemporary Brazil. New York : Nova Science. 
LIJPHART, A.; BRUNEAU, T. C.; DIAMANDOUROS, N. \& GUNTHER, R. 1988. A Mediterranean Model of Democracy? The Southern European Democracies in Comparative Perspective. West European Politics, v. 11, n. 1, p. 7-25, Jan.

MARTINS FILHO, J. R. 2006. State and Regime in Post-64 Brazil : Bureaucratic Authoritarianism or Military Dictatorship? In : CODATO, A. N. (ed.). Political Transition and Democratic Consolidation: Studies on Contemporary Brazil. New York : Nova Science.

MONCLAIRE, S. 2006. Democracy, Transition and Consolidation: Making Concepts More Precise. In : CODATO, A. N. (ed.). Political Transition and Democratic Consolidation: Studies on Contemporary Brazil. New York : Nova Science.

NAPOLITANO, M. 2006. A Chronology of Brazilian Political History : 1960/2002. In :CODATO, A. N. (ed.). Political Transition and Democratic Consolidation : Studies on Contemporary Brazil. New York : Nova Science.

OLIVEIRA, L. H. H. 2006. Paths to Democratization in Brazil : Consolidation of a Majoritarian Model of Democracy? In : CODATO, A. N. (ed.). Political Transition and Democratic Consolidation: Studies on Contemporary Brazil. New York : Nova Science.

POWER, T. J. 2006. Foreword. In : CODATO, A. N. (ed.). Political Transition and Democratic Consolidation : Studies on Contemporary Brazil. New York : Nova Science.

RODRIGUES, A. T. 2006. Autonomous Participation and Political Institutions in Recent Brazilian Democracy. In : CODATO, A. N. (ed.). Political Transition and Democratic Consolidation : Studies on Contemporary Brazil. New York : Nova Science.

SILVA, R. 2006. Delegative Democracy or Vicissitudes of Transition? In : CODATO, A. N. (ed.). Political Transition and Democratic Consolidation : Studies on Contemporary Brazil. New York : Nova Science. 